\title{
O lugar dos sujeitos: uma análise da questão da diversidade de gênero em estratégia de comunicação do Carrefour
}

\author{
El lugar de sujetos: una análisis de la questión de diversidad de \\ género en estrategia de comunicación de Carrefour
}

The place of the subjects: an analysis of the diversity of gender issue in Carrefour communication strategy

\begin{abstract}
Resumo
Este estudo tem por objetivo compreender como se dá a formação discursiva da construção do sujeito LGBT em uma estratégia de comunicação da multinacional Carrefour, a cartilha "Valorizamos a diversidade". Partindo-se do levantamento bibliográfico sobre a comunicação social enquanto espaço de disputa de sentidos, este estudo procura aproximar a área das relações públicas com os estudos de gênero, prospectando em que medida essas novas estratégias são parte de um processo de ressignificação de práticas comunicativas nas organizações, que passam a atuar em prol de um reconhecimento das questões de gênero. Através dos pressupostos metodológicos presentes em Pêcheaux (1988), este estudo também é um exercício sobre a análise do discurso do gênero nas organizações. Nessa perspectiva, entende-se esse processo como uma mudança simbólica nos sentidos que as organizações dão a suas estratégias e, ao mesmo tempo, um espaço que favorece o reconhecimento e visibilidade do grupo sociocultural LGBT nestes espaços.
\end{abstract}

Palavras-chave: Comunicação, Diversidade de gênero, Organizações, Análise do discurso.

\section{Resumen}

Este estudio tiene como objetivo comprender cómo es la formación discursiva de la construcción del sujeto LGBT en una estrategia de comunicación de la multinacional Carrefour, el folleto "Valoramos la diversidad." A partir de la literatura sobre los medios de comunicación como un espacio de sentidos de disputa, este estudio pretende abordar el ámbito de las relaciones públicas con los estudios de género, la prospección en qué medida estas nuevas estrategias son parte de un proceso de reformulación de las prácticas comunicativas en organizaciones, que ahora operan en favor del reconocimiento de las cuestiones de género. Através de los supuestos metodológicos presentes en Pêcheaux (1988), este estudio es también un ejercicio en el análisis del discurso de género en las organizaciones. En esta perspectiva, se entiende este proceso como un cambio simbólico en la forma en que las organizaciones dan a sus estrategias y, al mismo tiempo, un espacio que favorece el reconocimiento y la visibilidad del grupo sócio-culturales LGBT en estos espacios.

Palabras-clave: Comunicación, diversidad de género, organizaciones, análisis del discurso.

\begin{abstract}
This study aims to understand how the discursive formation of the LGBT subject occurs on a communication strategy of the Carrefour multinational, the primer "Valorizamos a diversidade". Starting from bibliographical

\footnotetext{
${ }^{1}$ Bacharela e mestranda em Comunicação Social, Universidade Federal do Paraná - Brasil, 
research about social communication as a space of dispute of senses), this study intends to approximate the area of public relations with the studies of gender, prospecting how this new strategies are part of a process of redefinition of communicative practices on organizations, which becomes to act towards the recognition of the gender issues. Through the methodological assumptions presented in Pêcheaux (1988), this study is also an exercise about the gender discourse analysis on the organizations. By this perspective, this process is understood as a symbolic change in the meanings that the organizations attribute to their strategies and also a place that benefits the recognition and visibility of the LGBT sociocultural group in those places.

Keywords: Communication, Gender Diversity, Organizations, Discourse analysis.

\section{Introdução}

As questões de gênero aquecem um debate nas mais diversas esferas da sociedade atualmente. Ainda este ano, alguns acontecimentos refletiram uma guinada na discussão, como a recente aprovação nos EUA do casamento igualitário entre pessoas do mesmo sexo que recebeu notória repercussão em redes sociais como o facebook no Brasil. Aqui, efervescendo na esfera pública posições contrárias a essa questão, o congresso nacional aprova o chamado Estatuto da Família, material que prevê a constituição familiar como somente possível entre pessoas heterossexuais. Passando para a esfera midiática, beijos homoafetivos em novelas tornam esses segmentos representativos, interpenetrando discussões cotidianas e movimentação social e política em torno desse grupo.

Nas organizações o que se percebe é também uma nova perspectiva comunicativa para agregar o público homoafetivo. Nesse sentido, objetivo deste estudo é compreender como o sujeito LGBT é ressignificado no discurso das organizações, especialmente no que tange a estratégias de comunicação para este segmento. É escolhida a cartilha da diversidade sexual da multinacional Carrefour, empresa que reflete uma organização inserida no contexto de globalização e de diferencial competitivo. A escolha metodológica parte do levantamento bibliográfico sobre os estudos de gênero nas ciências sociais, a partir do diálogo com os estudos da comunicação no campo das Relações Públicas e Comunicação Organizacional.

No objetivo de compreender como a estratégia intitulada Cartilha "Valorizamos a diversidade" pode ser vista como um fator preponderante para a inserção e reconhecimento de grupos minoritários como o LGBT dentro do espaço organizacional, faz-se uma análise do discurso segundo a linha francesa. Nessa perspectiva, pode-se inferir que há um processo de reconhecimento contra-hegemônico por parte desta organização, que dentro de um contexto capitalista de produção, reformula sua prática comunicativa para incluir em seu discurso segmentos historicamente invisibilizados da sociedade como o LGBT. 


\section{Comunicação e Relações Públicas: agentes estratégicos em ambientes organizacionais}

A moderna comunicação social compreende um campo de estudos voltado à reflexão crítica e científica de três principais práticas profissionais: o jornalismo, a publicidade e propaganda e as relações públicas. De formas diferentes, essas habilitações abrangem um mix de atividades que colocam a comunicação como ponto fundamental das relações sociais em todos os níveis, seja por interação face a face, mediada por dispositivos midiáticos ou, até mesmo, em um âmbito macro, de organizações para com seus públicos, respingando à construção de uma opinião pública, da formação de novas práticas culturais e hábitos de consumo na sociedade.

Não é novidade o potencial da comunicação enquanto espaço de construção de discursos e disputa de sentidos (BALDISSERA, 2008). Em um contexto de globalização no qual o ambiente socioeconômico aquece a busca por um diferencial competitivo, a comunicação se torna estratégica e fundamental para as organizações. Os discursos das organizações devem estar em consonância com aspectos de responsabilidade social, de reconhecimento de grupos culturais e étnicos, saindo assim em certa medida da lógica hegemônica lucrativa que sempre permeou os espaços organizacionais.

Nessa construção de sentidos, as organizações e seus públicos de relacionamento podem ser vistos como agentes de práticas discursivas responsáveis pelos sentidos atribuídos às ações comunicativas (OLIVEIRA; PAULA, 2008). Ou seja, a forma como se constrói o discurso das organizações na contemporaneidade passa a ser visto e avaliado por grupos tanto internos ou externos à organização. O seu feedback é termômetro para a organização planejar suas ações.

Nesse sentido, as modernas relações públicas representam, dentre as três habilitações, a atividade que reforça este espaço de troca entre organizações e seus grupos de relacionamento. Com o intensificar das trocas culturais e o surgimento de multinacionais e grandes grupos organizacionais, suas práticas fazem-se ainda mais necessárias neste contexto de globalização, ensejando-se de seus profissionais um olhar abrangente sobre as questões da atualidade, principalmente, voltadas à agitação cultural e política do momento ao qual está inserido.

Nos últimos anos, impulsionada por lutas sociais como as de gênero, de raça e etnia, grupos sociais minoritários como o LGBT passam a receber um olhar mais apurado das organizações e o campo de atividades das relações públicas se abrem a essas novas formações socioculturais. O que se tem percebido é uma nova locução por parte das organizações em 
relação à diversidade de gênero e sexual, provocando uma ressignificação nas estratégias de comunicação dessas organizações.

Essa nova locução passa por estratégias internas e externas às organizações, compreendendo políticas de comportamento organizacional, que afetam distintivamente o discurso das empresas e inferem em um processo de reconfiguração do sentido desses grupos para as organizações. Se anteriormente o que se notava era uma ausência desses grupos nas marcas estratégicas das organizações, atualmente se observa um investimento nesse público, desde campanhas e anúncios com a presença maior de mulheres, até a inserção de outros arranjos familiares que não o heterossexual, como a presença de casais gay em anúncios, campanhas e ações internas das organizações.

Porém, necessário é compreender a própria conceituação de gênero dentro deste processo, principalmente dentro dos estudos de gênero, que foram grandes propulsores da abertura dessa discussão em esferas diversas da sociedade, como a política, a acadêmica e também a organizacional. Entende-se, neste trabalho, que os estudos de gênero em diálogo com a comunicação são o pano de fundo para a compreensão dessas novas estratégias e desse novo discurso nas organizações acerca das pessoas LGBT.

\section{Estudos de gênero, grupos LGBTs e um novo campo para a comunicação}

Desde a fundação das disciplinas científicas que estudam o social, as diferenciações de sexo são objetos de estudo recorrentes. Porém, até meados de 1960, os estudos entendiam, em sua grande maioria, que as masculinidades e feminilidades tratavam-se de classificações universais e naturais, ou seja, inerentes a “espécie” humana (SUÁREZ, 1997, p 31).

Já a partir dos anos 1930, impulsionados pelas revoluções e a agitação social da época, surgem os primeiros estudos que reforçariam temáticas privilegiadas na atualidade pelas questões de gênero, como em Malinowski, Bateson e Mead, que explorariam a sexualidade e construção do feminino e masculino na organização social. Esses três autores, em antropologia, seriam os precursores dos estudos que analisariam a construção dos papéis sociais de masculino e feminino como construções de gênero.

Já na Sociologia, destacam-se as pesquisas pioneiras de Madeleine Guilbert, em 1946, que iniciavam uma investigação sobre o trabalho das mulheres (GUILBERT, 1946). No campo da Filosofia e da Literatura, Simone de Beauvoir publicou o livro O segundo sexo, em 1949, que gerou um debate político mais radical e lançou as matrizes teóricas de uma nova etapa do feminismo (BEAUVOIR, 1980). 
A palavra gênero, no entanto, só vem a surgir no espaço científico quando um movimento genuinamente feminino começa a prospectar a desnaturalização da condição da mulher na organização da sociedade. Diferentemente da visão naturalista e universal, a busca era pela compreensão dos papéis de homem e mulher como modelados culturalmente.

A essência masculina ou feminina era vista não como produto da sexualidade biológica, mas sim de distintas estruturas e relações de poder (SIMIÃO, 2000). Porém, este movimento no cenário acadêmico ficava estanque, recebendo, por vezes, descrédito: vinha de encontro a uma crítica à hegemonia masculina tanto no âmbito científico (a história sempre foi contada por homens) quanto à própria organização social, que funda instituições, leis e estruturas com pouquíssima inserção feminina, denunciando uma desigualdade latente. A relação com o movimento feminista que eclodia na agitação social da época também era alvo de descrédito acadêmico.

No entanto, inicialmente, dentro desta discussão, o termo gênero era considerado apenas como sinônimo de mulher. Só posteriormente, com a ampliação do campo de investigação científica, que a conceituação de gênero passou a abarcar uma relação com outras categorias como diferentes sistemas de gênero, que romperiam com o binarismo das categorias 'mulher' e 'homem'. Para Scott (1990), gênero é uma categoria de análise histórica, cultural e política, que expressa relações de poder. Essa conceituação permite o diálogo com outras categorias, como raça, classe ou etnia, e, também, levar em conta a possibilidade da mudança, inserindo-se aí as relações sociais de sexo e sexualidade também.

Um desmembramento singular do conceito de gênero foi dado, nesse sentido, segundo Scavone (2008), a partir dos anos 1990, pela chamada teoria queer, que 'ultrapassa os gêneros’ (transgendering), a cabo da filósofa feminista Judith Butler (2003). Seu estudo questiona o regime de normatividade heterossexual das sociedades, apresentando o aspecto socialmente transformável e relacional dos corpos e da sexualidade (gays, lésbicas, transexuais, travestis, bissexuais). Nesse sentido, os estudos queer inserem no guarda-chuva do conceito de gênero também os segmentos não heterossexuais, ou seja, concebendo-se aí e entendida nesse estudo como diversidade de gênero.

Nesse sentido, gênero, enquanto categoria para este estudo, adota-se a seguinte definição, proposta por Biroli e Miguel (2014, p. 79): “é a organização social da diferença sexual". O que não significa que reflita algo fixo; ao contrário, "gênero é o conhecimento que estabelece sentidos para as diferenças físicas". Entendido dessa forma, gênero não é uma "identidade", mas uma "posição social e atributo das estruturas sociais". Dessa maneira, a 
categoria LGBT enquadra-se como um segmento de gênero, um grupo social que possui determinada posição em relação à construção do discurso das organizações.

As organizações, quando se utilizam de um discurso que privilegia a diversidade de gênero em estratégias de comunicação, estão criando um ambiente, em certa medida, inédito para a área da comunicação, pois se trata da ressignificação dos espaços de fala destes sujeitos, e insere o conceito de gênero dentro do seu arcabouço teórico. Ora, se gênero é o conhecimento que estabelece sentidos para as diferenças físicas, a comunicação, com a inserção dessa questão em suas pautas, ações, estratégias, renova também, o seu sentido, constituindo-se como uma ferramenta para a ressignificação necessária ao enfrentamento que a temática ainda recebe em setores mais conservadores da sociedade. Por essa ótica, este estudo procura aproximar estas novas perspectivas em estratégias de comunicação para o segmento LGBT através do caso da Cartilha "Valorizamos a diversidade" do grupo Carrefour. O tópico seguinte destina-se a análise deste objeto.

\section{Diversidade de gênero nas organizações: o caso da cartilha "Valorizamos a Diversidade" do Carrefour}

O grupo Carrefour é uma rede internacional de hipermercados, fundada na França, em 1960. Em 2004, o grupo possuía dez mil unidades em trinta países e quatrocentos mil empregados. Configurada como uma multinacional de expressiva penetração em diversos países, o Carrefour trata-se de uma organização que se enquadra dentro da perspectiva de globalização e diferencial competitivo. No Brasil, o Carrefour é a segunda maior empresa varejista do país (segundo ranking do Ibevar em 2012), sendo o Brasil o primeiro país da América Latina a receber a loja Carrefour do continente americano.

Com o tempo e grande aderência no país, a rede expandiu-se, tornando-se uma das maiores empresas varejistas do país. Seus maiores concorrentes são o Grupo Pão de Açúcar e o Walmart. Ações de responsabilidade social estão presentes nos planejamentos e relatórios da organização desde sua adentrada no mercado brasileiro, como diferencial competitivo e de compromisso social. Somente para o ano de 2016, a estimativa é que a empresa invista 24 milhões em projetos sociais, valor anunciado em evento do Instituto Carrefour pelo diretor brasileiro do Instituto.

No ano de 2014, uma das ações internas do grupo Carrefour foi amplamente difundida em redes sociais e sites na internet, a chamada Cartilha "Valorizamos a Diversidade". Este material contém a visão da empresa em relação à diversidade sexual, mais especificamente no que diz respeito à pessoa LGBT (lésbicas, gays, bissexuais, travestis). Na cartilha a rede 
varejista comunica que travestis e transexuais "podem e devem" trabalhar ali e que seria contra os princípios do grupo "discriminar uma pessoa com base em orientação sexual ou identidade de gênero".

O manual também informa que pessoas do mesmo sexo podem se beijar em público como qualquer outro casal e que travestis e transexuais devem ser tratados pelo nome pelo qual se apresentam (e não o que está registrado no documento). Para o caso de essas pessoas serem colaboradores da companhia, o nome escolhido deve, inclusive, vir no crachá. "É uma questão de respeito e independe de decisão judicial ou cirurgia para mudança de sexo", pontua o texto. Segundo a direção do Carrefour no Brasil, o documento é divulgado internamente desde 2012 e faz parte do processo de "materializar" (ou seja: colocar em prática) a política de diversidade da empresa, no tocante a pessoas LGBT. Esta ação faz parte do código de ética mundial da companhia, que foi reformulado em 2010 visando atender a demandas de reconhecimento de questões de gênero e sexualidade.

O material elucida situações que ocorrem habitualmente dentro das lojas e qual é a postura que a empresa tem diante de tais situações. Casos de homofobia e discriminação são totalmente vistos como inaceitáveis dentro do ambiente organizacional, segundo a cartilha. Não somente o conteúdo exposto pelo material, a cartilha também faz parte de treinamentos dados a diretores, gerentes e coordenadores da rede, funcionando como instrumento de gestão da inclusão desses grupos. Para além do fato de ser uma comunicação de caráter estratégico, este material possui uma dimensão conscientizadora e educativa, que extrapola a lógica instrumental do manual como veículo meramente aproximativo.

Nessa análise, segundo a perspectiva da análise do discurso de linha francesa em Pêcheaux (1988) três pontos fundamentais são mapeados: o sujeito, a posição-sujeito e a formação discursiva (FD). Entende-se que esta metodologia está em consonância com o referencial de base, que entende a comunicação em ambientes organizacionais como um processo de disputa de sentidos (BALDISSERA, 2008).

Em Pêcheaux, a linguagem não é entendida apenas como um sistema de regras formais, estrutural. Nessa perspectiva, ela é pensada como simbólica, como uma "divisão política de sentidos" (BRASIL, 2011, p. 172). Segundo os critérios Pecheauxianos, este estudo se debruça sobre a busca de três aspectos fundamentais: o sujeito do discurso; a posição-sujeito, e a formação discursiva (FD). Entende-se que o mapeamento destes âmbitos nas duas estratégias elencadas permite inferir como ocorreu o discurso da diversidade de gênero nessas empresas. 


\subsection{Sujeito do Discurso}

Para Pêcheux (1988), o sujeito do discurso não se pertence, ele se forma pelo esquecimento daquilo que o determina. Isso significa que o sujeito não emerge como um personagem estanque, mas sim, como a interpelação deste indivíduo em relação à língua e à história: "pois para se constituir, para (se) produzir sentidos ele é afetado por elas. (...) Ou seja, se ele não se submeter à língua e à história, ele não se constitui, ele não fala, não produz sentidos (ORLANDI, 2005, p. 50).

Nos dois casos analisados, entendem-se os sujeitos do discurso como os grupos LGBTs, ou seja, indivíduos não heterossexuais. O sujeito apresenta aí viés histórico, pois trata-se de uma formação sociocultural que já existia muito anteriormente de ser reconhecida em âmbitos organizacionais, datando seu histórico de luta e reconhecimento político, bem como discussões a nível científico sobre suas pautas, etc.

Nesse caso, as organizações fazem-se valer, mesmo que intrinsecamente, a todo este histórico quando tornam visível este grupo através de suas ações comunicativas. Entretanto, esse histórico é causa próprio no interior de seu efeito, indo no sentido de acobertamento que Pêcheaux falava, quando outros recursos comunicativos se tornam mais explícitos que o próprio viés histórico do sujeito nas duas ações.

A Cartilha da Diversidade Sexual do Carrefour aborda o sujeito logo em seu enunciado primeiro: "Como lidar com pessoas LGBTs", contendo sete perguntas sobre situações que envolvam direta e indiretamente grupos LGBTs no ambiente organizacional. Não aborda a questão do histórico de opressão social e estigma que este grupo sofreu ao longo dos anos, porém, é na análise do discurso que este fator se salienta como algo dobrado nesta estratégia, ficando explícito somente com a análise. Neste ponto, identifica-se a posição do sujeito na estratégia, tópico que será visitado posteriormente. 


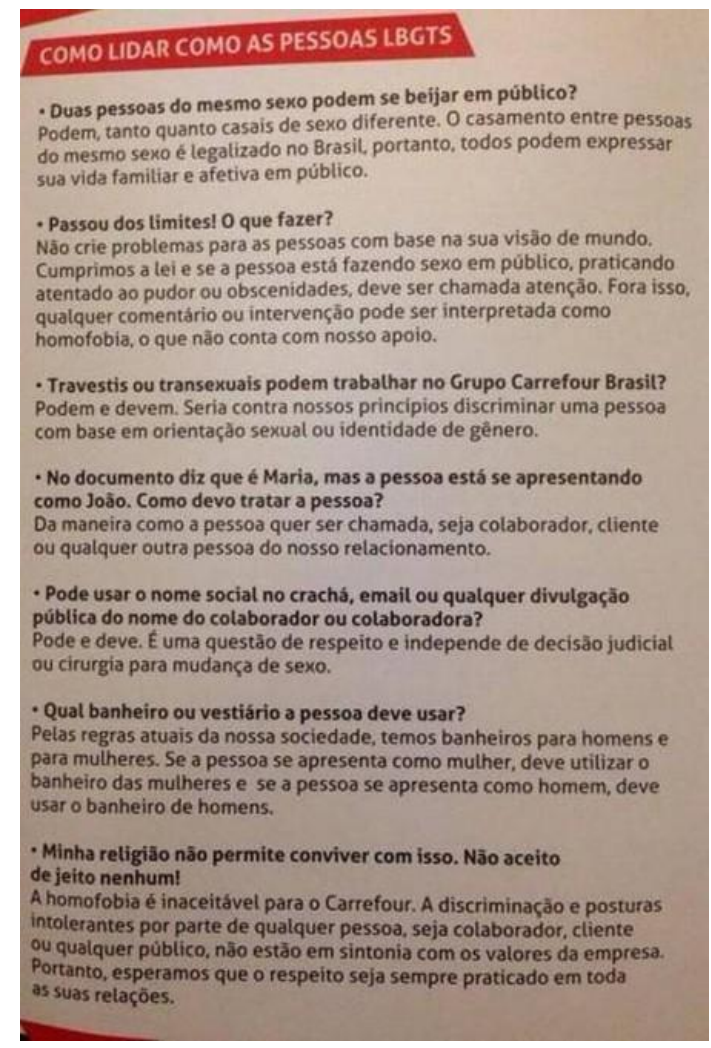

Figura 1 - Parte interna da Cartilha Valorizamos a Diversidade Carrefour.

Fonte: Divulgação Facebook

\subsection{A posição-sujeito}

A posição-sujeito (PÊCHEUX, 1988), em um sentido mais mutável que o apenas sujeito, "configura-se como um objeto imaginário que ocupa seu espaço no processo discursivo" (BRASIL, 2011, p. 172). Nesse sentido, o sujeito perde a razão de ser apenas um e abriga distintas posições, variando-se de acordo com a formação discursiva e ideológica intrínseca.

O sujeito LGBT está em diversas posições no caso da Cartilha da Diversidade, como um grupo que pode apresentar comportamento "condenável", ou como grupo que carece de respeito e reconhecimento para sua valorização. Essas duas formas observadas variam conforme o percurso que as perguntas estão dispostas, porém, a marca do estigma passa a ocorrer de forma velada. Nesse sentido, o sujeito não é mais um, mas comporta distintas posições-sujeito, variantes conforme as formações discursivas e ideológicas em que este se inscreve. 


\subsection{Formação discursiva}

O conceito de formação discursiva em Pêcheaux é oriundo de formulação elaborada por Michel Foucault (2004), que se relaciona à formação ideológica construída ao longo do discurso. Em outras palavras, o sujeito do discurso traz para o debate um grupo de representações individuais a respeito de si mesmo, do interlocutor e do assunto abordado. A FD, formação discursiva, é a projeção da ideologia no dizer (ORLANDI, 2005, p. 55). Passando para análise da formação discursiva, esta emerge na Cartilha da Diversidade Sexual do Carrefour colocando a discussão do gênero como não mais algo invisível ou velado na sociedade, propondo o seu reconhecimento e ressignificação deste grupo historicamente condicionado à desigualdade.

Entende-se, então, que o grupo LGBT constitui-se como sujeito a partir do momento em que se torna presente, visível, nesta estratégia. Ainda que, em certa medida, de forma tímida, o sujeito está ali interpelado por sua história e ideologia, que transcende o mero agregar valor ao produto e à lógica competitiva da organização estudada.

\section{Conclusões}

Este estudo procurou, motivado pelo compromisso social que a pesquisa científica também deve ter, compreender como as organizações abordam a temática da diversidade de gênero em suas estratégias de comunicação atualmente. $O$ ensejo deste estudo, antes de tudo, foi a tentativa de um exercício de aproximar da comunicação social esta problemática tão recorrente na sociedade atual que são as discussões de gênero.

Neste escopo, o que se observou, é uma abrangente e complexa nova forma de fazer comunicação levando em consideração essa problemática e, também, da própria comunicação como uma alternativa ao reconhecimento e legitimação dessas questões. O momento político e cultural é oportuno para as organizações, que cada vez mais repensam suas práticas e ressignificam suas lógicas de lucro em prol do reconhecimento de grupos não hegemônicos e minoritários como o LGBT. Especificamente no que concerne a eles, a fusão comunicação, organizações e gênero pode ser um âmbito profícuo de reforço de identidades estigmatizadas, de conscientização e valorização da diferença. É na dimensão comunicativa que as organizações podem corroborar para uma sociedade mais justa e igualitária em relação às questões de gênero.

Da mesma forma, para serem vistas com credibilidade por seus públicos, as organizações precisam assumir também a sua função política que, nas palavras de um teórico das relações públicas, pode ser compreendida como: "a contribuição que elas devem dar para 
a manutenção da continuidade do sistema social do qual elas fazem parte, o que só lhes será possível se, da lógica econômica, elas migrarem para a lógica social.” (SIMÕES apud FERRARI, 2011, p. 141).

\section{Referências bibliográficas}

BALDISSERA, R. Comunicação organizacional: uma reflexão possível a partir do paradigma da complexidade. In: OLIVEIRA, I. L.; SOARES, A. T. N. (Orgs.). Interfaces e tendências da comunicação. São Caetano do Sul: Difusão, 2008.

BIROLI, Flávia. MIGUEL, Luis Felipe. Feminismo e política: uma introdução. Brasília: Boitempo, 2014.

BUTLER, Judith. Problemas de gênero. Feminismo e subversão da identidade. Rio de Janeiro: Civilização Brasileira, 2003.

BRASIL, Luciana Leão. Michel pêcheux e a teoria da análise de discurso: desdobramentos importantes para a compreensão de uma tipologia discursiva. Linguagem: estudos e pesquisas. Vol. 15, n. 1, p. 171-182, jan/jun, 2011.

OLIVEIRA, I. L.; PAULA, C. F. C. Comunicação no contexto das organizações: produtora ou ordenadora de sentidos. In: OLIVEIRA, I. L.; SOARES, A. T. N. (Orgs.). Interfaces e tendências da comunicação. São Caetano do Sul: Difusão, 2008.

ORLANDI, Eni Puccinelli. Análise de discurso: princípios e procedimentos. 6. ed. Campinas, SP: Pontes, 2005.

PÊCHEUX, Michel. Semântica e discurso. Campinas: Pontes, 1988. SCOTT, Joan W. Gênero: uma categoria útil de análise histórica. Educação e Realidade, Porto Alegre, v. 16, n. 2, jul./dez, 1995.

SUÁREZ, Mireya. A problematização das diferenças de gênero e a antropologia. In: AGUIAR, Neuma (Org.). Gênero e ciências humanas: desafios às ciências desde a perspectiva das mulheres. Rio de Janeiro: Record; Rosa dos Tempos, 1997.

FERRARI, Maria Aparecida. O cenário das organizações como sistemas de significados socialmente construídos. In: GRUNIG, J. E; FERRARI, M. A; FRANÇA, F. (Orgs.).

Relações Públicas: teoria, contexto e relacionamentos. São Caetano do Sul. SP: Difusão, 2011. 